\title{
Estimation of Cephalometric Norm for Bangladeshi Children (Steiners Method).
}

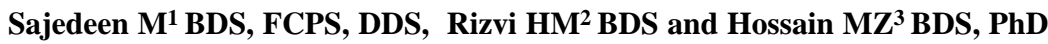

\begin{abstract}
Objective: The objective of this study was to establish cephalometric norms of Bangladeshi children age range (10-13years) and to compare it with accepted standards for the Caucasian population according to Steiner analysis.

Methods: Fifty healthy Bangladeshi children both male and female, with a mean age of 12.3 years, were selected from different schools of Dhaka. Selection was made on the basis of normal occlusion, balanced and pleasing profile with no obvious facial asymmetry. None of the children have undergone orthodontic treatment prior to this study. Lateral skull cephalograms were taken and traced using a standardized technique. Each cephalogram was traced twice with a one week interval by the authors. All angular and linear measurements were calculated to the nearest 0.5 degree and $0.5 \mathrm{~mm}$, respectively. Steiner's method of cephalometric analysis was used to establish cephalometric norms.

Results: A comparison of the results with the Steiner standards showed that the Bangladeshi children were more protrusive skeletally and dentally with a greater tendency towards bimaxillary protrusion. Further, there was a decrease in the lower facial height.

Conclusion: The results of the study support the fact that norms and standards of one racial group could not be used without modification for other racial group and each different racial group would have to be treated according to its individual characteristics.
\end{abstract}

Keywords: Cephalometric norms, analysis, racial group. (Ban J Orthod \& Dentofac Orthop, October 2010; Vol-1, No. 1,1-4)

\section{INTRODUCTION}

After the invention of Cephalometric radiography Lucien de Coster of Belgium was first to publish an analysis based on proportional relationships in the face. Thereafter many methods followed in rapid succession.1,2 One of the first and widely used Cephalometric analyses was by Downs and was designed to illustrate the spreads of all measurements of an individual by plotting these values on a chart. ${ }^{3}$ Steiner developed his analysis with the idea of providing maximal clinical information with the least number of measurements. The analysis is divided in three parts, skeletal, dental and soft tissue analysis. ${ }^{4}$ Morphologic variations among different races and ethnic groups are not distributed randomly but seen in geographic clusters. There seems special physical charecterestic among people of different races which is completely unlikely to others. People residing geographically different locations have differences in morphologic charectrerestics and migratory people carry these characterestic with their journey to a different place and uphold those until there is cross racial marriage.

After the introduction of roentgenographic Cephalometry in orthodontics, methods have been used to establish the Cephalometric norms of different ethnic groups: American Negro, Australian aborigine, American Mexican, Norwegian, Indian, Japanese, Swedish, and Iranian. Sassouni,5,6 Ricketts, 7 and others have concluded that norms differ between Caucasians and other ethnic and racial groups.1,2 Ethnic differences in facial traits do exist. Awareness of the normal dentofacial pattern of each ethnic group will undoubtedly ensure better success of treatment to establish optimal facial harmony. These conclusions prompted the need of my proposed field of study to dentofacial patterns and provide information on the facial characteristics of Bangladeshi people. Cephalometric norms can be invaluable aids to the practitioner in determining patient abnormalities. Norms define ideal Cephalometric measurements for a patient, based on such factors as age, sex, size, and race. If the patient deviates from a norm by a margin greater than that prescribed by the clinician (usually one standard deviation), this information should influence diagnostic and treatment-planning procedures.2,8,9,10

This norm will guide Orthodontic treatment in many ways. Using direct observation clinician can learn to recognize patients with significant mandibular retrusion , mandibular prognathism , long \& short facial heights, and excessive vertical growth of maxilla.2,11 These features are associated with three facial profile types; straight, convex and concave. Cephalometric radiograph enables clinicians to quantify facial and dental relationship and thereby assess more accurately the extent to which a patient deviates from normal facial and dental morphologies. By comparing anatomic relationships in an individual patient to the relationships found in a group of persons with normal occlusion, the normality of the patient can be determined. ${ }^{9}$ The normality of a patient is evaluated by relating the angular and distance measurements taken from the cephalogram to normatic Cephalometric values obtained from a sample of normal peers. The patient should belong to the same population from which the normative sample was taken. For each angle or distance, the mean, standard deviation, , range (maximum \& minimum value)are recorded. The mean value is a mathematical central point derived from measurements taken from many individuals. None of the individuals of the norm group were likely to have a measurement identical to the mean. Because variability is basic to human physiognomy, the likelihood that any patient will have several of the mean values is remote. So all measurements falling within 1 standard deviation above and below the mean are considered normal. $1,13,14$

${ }^{1}$ Assit. Prof., Department of Orthodontics \& Dentofacial Orthopedics, Dhaka Dental College. ${ }^{2}$ FCPS part II trainee, Department of Orthodontics \& Dentofacial Orthopedics, ${ }^{3}$ This study was supervised by Professor \& Head, Department of Orthodontics \& Dentofacial Orthopedics, Dhaka Dental College. 


\section{MATERIALS \& METHODS}

\section{Study design}

A cross sectional study was carried out to evaluate the Cephalometric norm of Bangladeshi children. Steiner analysis were followed.

\section{Place of study}

The study was carried out in the department of Orthodontics, Dhaka Dental College \& Hospital, Mirpur-14, Dhaka-1206

\section{Study Population}

Eligible subjects were those whose age range from 10 years to13 years with normal occlusion. Both male and female were included in the study. Sample size was 50 .

\section{Inclusion criteria}

The criteria to be followed in sample selections are Bangladeshi children with

1. Good health

2. Same age range

3. Acceptable facial relationship with normal lip seal

4. Angle Class I molar and canine relationships (bilateral) with incisor contact and well aligned teeth and

5. No history of previous orthodontic treatment. Minor rotation or slight overjet and overbite were acceptable

\section{Exclusion criteria}

1. Non cooperative children

2. Other than class I occlusion

3. Incompetent lip or any soft tissue abnormality

4. Any history of Orthodontic treatment

\section{Period of study}

Total duration of the study was July 2005 to June 2007.

\section{Study procedure}

Each of the subjects was selected by examining extra orally and intra orally. After the exclusion and inclusion criteria were fulfilled the subjects were selected. A case history sheet for each was filled. Then each was referred for a cephalogram.

Each cephalogram was traced and angular and liner measurements were recorded. To assess tracing errors , a 2nd tracing was prepared after one week interval. The mean error in linear measurements was $+1 \mathrm{~mm}$. The mean error in angular measurement was $+1^{\circ}$.

\section{METHOD OF DATA COLLECTION}

Data were collected samples that fulfilled the inclusion and exclusion criteria. An interview was carried out with the help of history sheet and face to face interview method. Then a cephalogram was taken . Each cephalogram was assessed to meet the standardization .Then each cephalogram was traced \& analyzed. The required values were recorded.

\section{Data processing}

After completion of the data, the obtained data was checked, Verified \& edited. The data were entered in a personal computer using the MINITAB program. Entered data were cleaned , edited and appropriate statistical test were done depending on the distribution of data.

\section{Data Analysis}

This cross sectional study was conducted among 50 Bangladeshi children aging from 10 years to 13 years (mean age 12.3 years) with normal occlusion and good facial proportion. Aim was to find out the Cephalometric norm of Bangladeshi children. After editing the data was analyzed with the help of software MINITAB.

\section{Type of study}

Cross sectional.

Table I: Steiner analysis

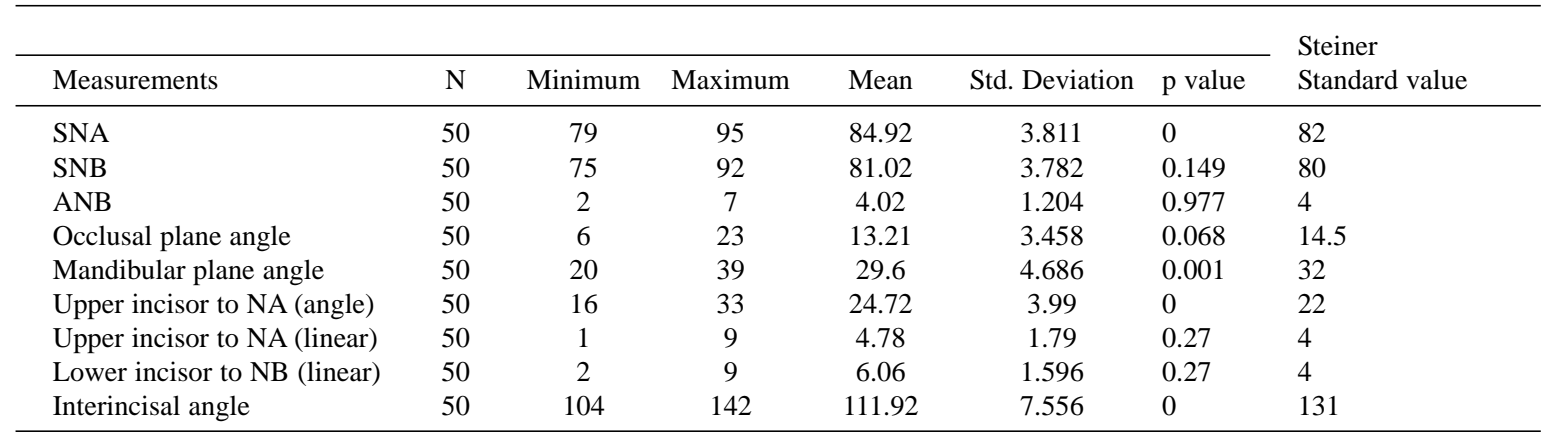

Table 1: Different measurements over Steiner analysis.

N.S. $=$ Not significant $(\mathrm{P}>0.05) \mathrm{P}<0.05=$ Significant at $5 \%$ level $\mathrm{P}<0.01=$ Significant at $1 \%$ level $\mathrm{P}<0.001=$ Significant at $0.01 \%$ level. 
S- line:

According to Steiners S- line percentage of protrusive face is $56 \%$, Normal face is $40 \%$ and retrusive face is $4 \%$ among the samples. ( Table 2,)

Table II: Frequency of facial profile type

\begin{tabular}{lcc}
\hline Type of face & Frequency & Percentage \\
\hline Normal & 20 & 40 \\
Protrusive & 28 & 56 \\
Retrusive & 02 & 04 \\
\hline
\end{tabular}

\section{DISSCUSSION}

Considering the ethnic back ground of patients in setting treatment objectives is an important requirement for successful orthodontic treatment. This can be achieved by establishing Cephalometric and facial norms of different racial groups. Unfortunately no studies on Bangladeshi children for Cephalometric norm was done. This study may be considered the first trial. The cross sectional study was conducted in the department of Orthodontics and dentofacial orthopedics, Mirpur 14, Dhaka, to establish the Cephalometric norm of Bangladeshi children. The subjects of the study were selected on basis of inclusion and exclusion criteria. Among the initially selected 250 samples 50 were finally chosen on random selection basis. The age group included from 10 years to 13 years age consisting of 12 years to 12 years 11 month comprise of $44 \%$ of the sample. The next highest is from 13 years to 13 years 11 month (24\%) followed by 11 years to 11 years 11 month (18\%) \& 10 years to 10 years 11 month. On cross check study no change was found over the variables due to age variations. This study correlates with the study conducted on Saudi children .18

Males and females were both included in the study. A slightly more number of females were found in the population which was about $58 \%$ and male population was about $42 \%$. There was no statistically significant difference between Bangladeshi male and female children. Cephalometric comparisons of the dentofacial relationships of two adolescent populations from Iowa and Northern Mexico was done by Samir E. Bishara, and Arturo Garcia Fernandez, found significant differences between boys and girls within each population in the skeletal linear parameters of both the anterior and posterior face heights.11,15

Cephalometric evaluation of Iranian children and its comparison with Tweed's and Steiner's standards was done by Mohammad Hajighadimi., Harry L. Dougherty, and Farimah Garakani, 16,17 skeletally; there were no significant differences between Iranian girls and boys. However, in the male group the dentition was more procumbent than in the female group. In the study done by Ali H. Hassan on western region of Saudi children correlates with our study. There was no statistically significant difference between male and female group. ${ }^{14}$ May be a wider variation of age in the sample could produce significant change in cross check with the variables.
The result of the present study showed that the Bangladeshi children have slightly high mean value statistically significant for Sella-Nasion-Point A angle (SNA) while the Sella-Nasion-Point $\mathrm{B}$ angles (SNB) was relatively similar to the mean value reported by Steiner. Also, the same was observed for the Point ANasion-Point B angle (ANB) Nasion-Sella (NS) to Occlusal plane (OP). However, the upper incisors to NA (Nasion-Point A plane) line and the lower incisor to NB (Nasion-Point B plane) line indicates a bimaxillary protrusion with a decreased interincisal angle. The lower jaw inclination indicates that the angle was smaller than the Steiner's norm. From this study it can be said that the Bangladeshi children exhibited a more horizontal growth pattern than the Caucasians, a decrease in the lower facial height.[Table 1]

In soft tissue analysis, 56\% cases upper and lower lips are found anterior to S-line giving a protruded appearance. [Table 2]

According to Steiners S-line soft tissue profile of Bangladeshi children has a tendency of protrusive profile over normal profile. [Fig-1]

A.

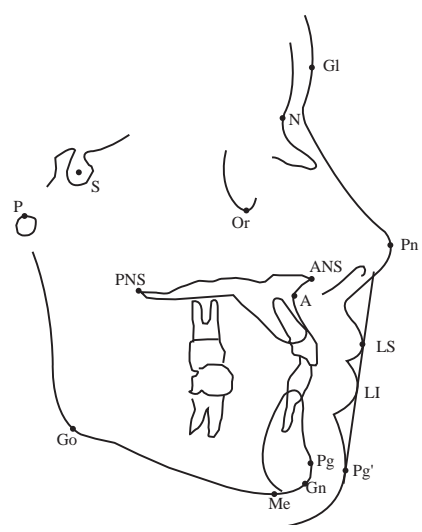

B.

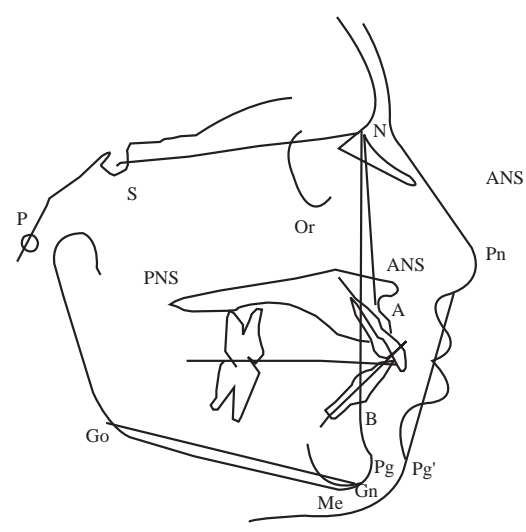

Figure 1: Two Cephalometric analyses: (A) showing the position of S- line in the Steiners analysis \& (B) showing the position of $\mathrm{S}$ line of a subject in this study, (Note the projection of both the lips in front of Steiner S -line) 


\section{CONCLUSION}

This type of study was not done in our country. So this may be regarded as an initial step. It may somehow guide planning of this type of study in future more accurately. Special criteria such as bi maxillary proclination tendency of the subjects brought into account the need of planning a lesser interincisal angle in finishing stage. Similarly a slight bi maxillary proclination should be considered as normal. The mean values found in the study would guide diagnosis, treatment planning and setting treatment goal in our every day practice in the field of Orthodontics .

\section{REFERENCES}

1. Jacobson A.Radiographic Cephalometry from basis to videoimaging, 1st edition Quintessence Publishing Co.Inc;1995

2. Downs WB. Variations in facial relationships: their significance in treatment and prognosis. AM J ORTHOD 1948,34:812-40.

3. Steiner, C. C.: Cephalometrics for you and me, AM. J. ORTHOD. 39: 729-755, 1953.

4. Bishara S. E. Textbook of Orthodontics 1st edition W.B.Saunders Company 2001

5. Argyropoulos E., Sassouni, , Comparison of Greek and American dentofacial patterns - Volume 1989 Mar (238 - 249):

6. Graber TM., Vanars dall RL jr. Orthodontics current principles and techniques, 3rd edition Mosby, St. Lous; 2000

7. Ricketts, Robert: Cephalometric analysis and synthesis, Angle Orthod. 31: 141-156, 1961.

8. Broadbent BC. The face of the normal child. Angle Orthod 1937; 7:183-208.

9. Profit WR. , Fields H. W. contemporary Orthodontics 3rd edition. Mosby, St. Lous; 2001
10. Broadbent BC. A new x-ray technique and its applications to orthodontia. Angle Orthod 1931;1:45-6.

11. Bishara SE, Fernandez AG. Cephalometric comparisons of the dentofacial relationships of two adolescent populations from Iowa and Northern Mexico. AM J ORTHOD 1985;88:314-22.

12. Krogman WM, Sassouni V. Syllabus in roentgenographic cephalometry. Philadelphia Center for Research in Child Growth, 1957.

13. Argyropoulos E, Sassouni V. A cephalometric appraisal of Greek adults [Unpublished report]. University of Pittsburgh, 1983.

14. Hassan A. H. Cephalometric norms for Saudi children living in western region of Saudi Arabia: a resear reort Head \& face Medicine 2005,1:5

15. Garcia CJ. Cephalometric evaluation of Mexican Americans using the Downs and steiner analysis. AM J ORTHOD 1975;68:67-74.

16. Hajighadimi M, Dougherty HL, Garakani F. Cephalometric evaluation of Iranian children and its comparison with Tweed's and Steiner's standards. AM J ORTHOD 1981;79:192-7.

17. Richardson E. Racial differences in dimensional traits of the Human face. Angle Orthod 1980;50:301-11.

18. Hassan A. H. Cephalometric norms for Saudi children living in western region of Saudi Arabia: a resear reort Head \& face Medicine 2005,1:5

\section{Correspondence}

Dr Mahmood Sajedeen, BDS, DDS, FCPS

Asstt. Professor, Department of Orthodontics, Dhaka Dental

College, Dhaka, Bangladesh.

E-mail: drmasa@yahoo.com, Cell: +88 01715006398 